\title{
Militarización de la escuela chilena a principios del siglo XX. El modelo alemán Bávaro en tierras Mapuches
}

\author{
Militarização da escola chilena no começo do século XX. \\ 0 modelo alemão de Bávaro em terras Mapuches \\ Militarization of the chilean school at the beginning of the 20th century. \\ The german Bávaro model in Mapuche lands \\ JUAN MANSILLA SEPÚLVEDA \\ CATALINA RIVERA GUTIÉRREZ
}

\begin{abstract}
Resumen: Este artículo busca comprender la actuación pedagógica de los misioneros capuchinos bávaros y el disciplinamiento que ejercieron a través de las escuelas misionales e internados de los cuerpos de niños mapuches. La investigación es de carácter exploratoria-descriptiva y analiza fuentes primarias, escritas y visuales, encontradas en archivos en Chile y Alemania. Los resultados del estudio evidencian rasgos militares en ideario formativo capuchino, lo que se evidencia en las vestimentas y modos de disposición del cuerpo a las que fueron obligados a practicar niños mapuches en la primera mitad del siglo XX en la región de la Araucanía en Chile.
\end{abstract}

Palabras-clave: educación militarizada-capuchinos alemanes- niños mapuchedisciplinamiento del cuerpo

Resumo: Este artigo procura investigar a prática pedagógica dos missionários capuchinhos da Baviera e a disciplina que exerceram nos corpos das crianças mapuche, dentro das escolas missionárias e internatos. A pesquisa é exploratória e descritiva e analisa as principais fontes escritas e visuais encontradas em arquivos no Chile e na Alemanha. Os resultados do estudo mostram características militares na ideologia formativa capuchinha, evidenciadas pelas maneiras pelas quais as crianças mapuche foram forçadas a viver na primeira metade do século XX na região de Araucanía, no Chile.

Palavras-chave: educação militarizada-capuchinhos alemães- crianças mapuchedisciplina corporal

\begin{abstract}
This article aims to understand the pedagogical performance of the Bavarian Capuchin missionaries and the discipline they exercised on the bodies of Mapuche children through the missionary and school boardings. The research is exploratory-descriptive and analyzes primary sources, written and visual, found in archives in Chile and Germany. The results of the study show military features in a Capuchin formative ideology, which is evidenced in the clothing and body disposition modes to which Mapuche children were forced to practice in the first half of the 20th century in the Araucanía region of Chile.
\end{abstract}

Keywords: militarized education, German Capuchins, Mapuche children, Body discipline 


\section{INTRODUCCIÓN}

El presente trabajo forma parte de una investigación situada desde el Proyecto Fondecyt Regular N ${ }^{\circ} 1190034$ financiado por la Comisión Nacional de Ciencia y Tecnología (CONICYT-Chile) denominado "Consolidación de la escuela monocultural en territorio mapuche en el periodo post-reduccional (19291973). Colonialidad republicana e invisibilización del mapuche-kimun”. A través de esta investigación se pretende visibilizar como la idea de militarización de la enseñanza ha estado presente implícitamente en diversas propuestas curriculares en la historia de la educación en Chile. Si bien es cierto, explícitamente no se ha declarado instalar idearios formativos como el Programa Nacional de escuelas ć́vico-militares, -impulsado por el actual Presidente de Brasil Jair Bolsonaro-, históricamente han existido en la práctica rutinas y valores cívico militares en escuelas de la Región de La Araucanía en el periodo inmediatamente posterior a la ocupación del territorio mapuche, discursos y prácticas relacionadas, las cuales podríamos denominar como currículo oculto de las escuelas. Lo anterior se debe comprender en el contexto de un territorio-como es el caso mapucheque fue autónomo desde 1641, reconocido legalmente por la corona española, situación que se mantuvo hasta 1881, hito de la derrota sufrida por el pueblo mapuche ante el Estado Chileno, que culmina con la fundación de Temuco. Por consiguiente, asistimos a un proceso en que el Estado de Chile necesita chilenizar y evangelizar a los habitantes de un espacio donde la presencia del Estado había estado ausente. En este sentido, los misioneros capuchinos bávaros cumplieron ese rol eficientemente y de modo estratégico.

\section{EL ESTADO CHILENO OCUPA POR LA FUERZA EL TERRITORIO MAPUCHE}

En la segunda mitad del siglo XIX, el Estado liberal chileno incorporó por la fuerza al territorio nacional el espacio denominado Araucanía (Wajmapu), ocupado ancestralmente por el pueblo-nación mapuche. El wajmapu es el territorio ancestral del pueblo mapuche, entendido como el círculo en que estamos viviendo y que se representa simbólicamente por el kuxug, representación del mundo mapuche. En la actualidad, la denominada Frontera Mapuche contempla las regiones del Biobío, La Araucanía y Los Ríos, en el centro sur de Chile.

La integración de la Araucanía a Chile, inaugura un proceso de ocupación de tierras donde terminan imponiéndose los proyectos modernizadores que propiciaban los grupos dirigentes del centro del país, y la consiguiente política inmigratoria promovida desde el Estado. (MANSILLA, LLANCAVIL, MIERES; 
MONTANARES, 2016). En este escenario, congregaciones religiosas de diferente confesionalidad desempeñaron un papel relevante para que los indígenas -que en estricto rigor constituyeron "las primeras naciones"-, superaran el "paganismo salvaje" y la "ignorancia cultural", y por tanto, sean educados, "civilizados según el canon occidental" desde la escuela, con una disciplina cuasi militar. De este modo, aparece la triple estrategia para concretar el afán darwinista social, a saber: escuela, misión e internado, promovida por los capuchinos bávaros alemanes para vehiculizar este discurso civilizatorio del Estado nacional y lograr someter el cuerpo del otro totalmente, militarizando la educación a partir de ritos patrióticos, vestimentas uniformadoras y reglamentos de diversa índole.

En este proyecto civilizador fue primordial construir una imagen del "otro" como un buen salvaje, al que se debía civilizar y difundir por el mundo a través de fotografías plasmadas en tarjetas postales que mostraban aquellos cuerpos que estaban en procesos de disciplinamiento y buen encausamiento en las diversas escuelas e internados de la Araucanía (TODOROV, 2008). En esta narrativa de los grupos dirigentes de Chile, la idea de civilización se simboliza por un conjunto de atributos considerados positivos tales como: "Europa, ciudad, occidente, espíritu, luz, racionalidad, familia, escuela, higiene, sabiduría, amor, día, belleza, cristianismo, blanco, bueno, sano, limpio, progreso, etc. Mientras que barbarie fue la noción maestra que englobó un conjunto de términos directamente negativos, entre los cuales están "América, campo, cuerpo, oscuridad, mapuche, poligamia, instinto, ignorancia, odio, noche, tinieblas, fealdad, paganismo, negro, malo, enfermo, sucio, atraso, etc." (DE LA BARRA, 2000; AZÓCAR, NITRIHUAL, FLORES, LÓPEZ Y PACHECO, 2015; MANSILLA y QUILAQUEO, 2018)

Del mismo modo, en ese proceso la figura del misionero fue clave como agente de civilización ideológica, cultural y política. Existió, entonces, una imbricación robusta entre evangelización y escolarización con foco en la asimilación cultural mediante el uso de la lengua dominante (HOT, 2010; SARANGAPANI, 2014; TUBINO, 2014; CATRIQUIR, 2014).

Asimismo, a fines del siglo XIX la educación chilena vivió el proceso que se conoce como el "embrujo alemán". Por tanto, la educación en Chile en el último tercio del siglo XIX transitó hacia un nuevo paradigma cultural y epistemológico, siempre buscando las respuestas y los modelos pedagógicos en Estados Unidos o Europa. Es el ocaso del ciclo de la influencia francesa que caracterizó de modo gravitante a la cultura iberoamericana de la post-independencia y, por cierto, a Chile, país que no pudo sustraerse a este fenómeno (KREBS y GAZMURI, 1990) Lo anterior se evidencia con las visitas realizadas a Alemania por dos autoridades pedagógicas de la época, José Abelardo Núñez y Valentín Letelier Madariaga. La atención de Letelier se focalizó en la formación del profesorado de educación 
secundaria. Letelier dedicaría dos obras a la educación secundaria y universitaria. En el libro-memoria, publicado en 1885, se sistematizan las anotaciones realizadas después de visitar algunos establecimientos de educación secundaria y universitaria en Berlín (LETELIER, 1885; MANSILLA y HUAIQUIÁN, 2018). En 1882 Valentín Letelier fue enviado a Berlín como miembro de la legación chilena en la capital alemana. Hizo de su misión en Berlín una estancia de investigación con la finalidad de descubrir los elementos que podían ser copiados y transferidos a Chile para que este país mejorara su cultura (LETELIER, 1885). En ese tiempo, la educación secundaria en Alemania se organizaba desde mediados del siglo XVIII en dos tipos de escuelas: la "Escuela Real" (Realschule) y el "Jimnasio" (Gymnasium). Las primeras escuelas nacieron como alternativa práctica al "Gimnasium", tradicionalmente humanista y en los que se consideraba deshonroso el conocimiento útil.

El Gimnasium se reservaba casi exclusivamente a los futuros altos funcionarios y miembros de la elite que ya habían asistido a una escuela básica de renombre y aspiraban a hacer una carrera universitaria, mientras que la Realschule formaba a técnicos y burócratas de rango medio y bajo "con escasas posibilidades de ascenso en la escala social debido a que, en contadas ocasiones tenían acceso a la universidad" (LETELIER, 1885, p. 80). Esta experiencia sedimentará en la ideología educacional de Valentín Letelier, una enorme admiración por la filosofía pedagógica herbartiana, en la que se enfatiza la necesidad de la formación de un profesor como pedagogo para así lograr clases efectivas (CORIAND Y WINKLER, 1998). Aquí encontramos las bases epistemológicas de las prácticas disciplinarias cuasi militares de las diversas congregaciones alemanes que llegaron a Chile, tanto al campo como en la ciudad, indistintamente si eran colonos, religiosos luteranos o de confesionalidad católica, sacerdotes o "monjitas".

\section{LA LLEGADA DE LOS MISIONEROS CAPUCHINOS BÁVAROS ALEMANES A LA ARAUCANÍA}

Los capuchinos pertenecen a la "familia franciscana" y por tanto, son hijos de Francisco de Asís y seguidores de Cristo a la manera de Francisco. Como éste, comprenden y proyectan su labor misionera y evangelizadora, desarrollando una forma específica, aunque no exclusiva, de dicha tarea. Francisco de Asís plantea que los religiosos deben ir "entre los sarracenos y otros infieles", el concepto central está dado en esta idea fuerza de ir "entre" y no solamente "ir". Así las cosas, el misionero no puede ser sólo un peregrino o predicador ambulante, debe ir a integrarse, incorporarse a la forma de vivir de los sarracenos e infieles (léase mapuches). Estar con, vivir entre, es la propuesta y desde allí anunciar el 
Evangelio (FLORES Y AZÓCAR, 2002). Este mandato de las constituciones apostólicas de los capuchinos fue cumplido con creces, no sólo fueron "entre", sino, incluso aprendieron el idioma mapuzungun y lo enseñaron, como el caso de Félix de Augusta.

Fig.1. Escuelas Misionales Capuchinas para externos e internados en 1938

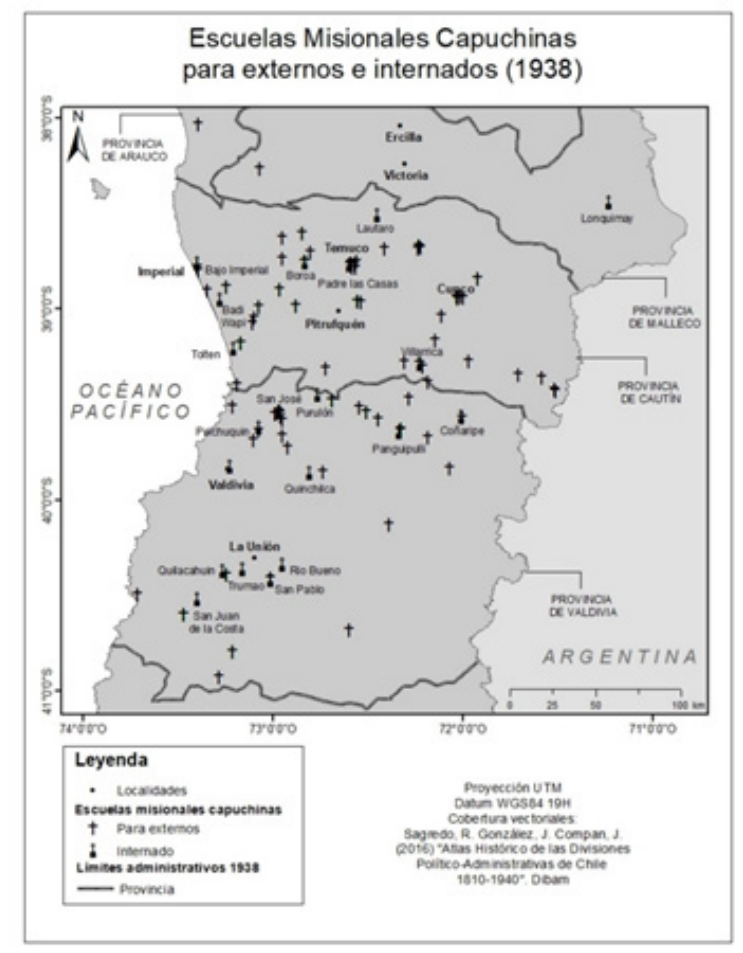

El 6 de noviembre de 1895 se embarcaron en Hamburgo los cuatro primeros capuchinos bávaros que llegaron a La Araucanía: el sacerdote Anselmo de Kamin (futuro párroco de Boroa y fundador de Padre Las Casas), el sacerdote Félix José de Augusta (Médico de origen judío alemán), el sacerdote Tadeo de Wiessent (famoso por la aplicación del método hidroterápico) y el hermano Sérvulo de Gottmannshofen. Viajaron desde Hamburgo hasta Buenos Aires, y después a Santiago, llegaron el 20 de diciembre. Luego viajaron a Valparaíso, donde el 4 de enero embarcaron en un vapor que los llevó a Corral. Desde ahí, el mismo día de su llegada viajaron en barco por río hasta Valdivia. Fueron recibidos por el párroco de Valdivia, José Brahm, quien se ocupó de los nuevos misioneros y les enseñó castellano durante seis semanas. El 16 de febrero de 1896 viajó el padre Félix con el hermano Sérvulo a Bajo Imperial (Actual Puerto Saavedra) en 
el espacio costero de La Araucanía. Hicieron a caballo el viaje por San José de la Mariquina y Toltén, se demoraron alrededor de 10 horas. Fueron recibidos por el padre Juan en Toltén. Descansaron unos días y los acompañó a Bajo Imperial, donde les hizo oficialmente entrega de la misión. Así se instalaban los capuchinos bávaros en la región de La Araucanía (RÖTTINGEN, 1921). En este contexto, Félix de Augusta escribe por primera vez al Prefecto el 5 de marzo de 1896: “[...] difícil es saber qué hacer por el momento, sin la ayuda de hermanas para educar a los niños, no me prometo avances significativos" (RÖTTINGEN, 1921). Más tarde llegarán las hermanas de la Santa Cruz, haciendo eco de esta petición. En todas partes se abrieron escuelas misionales.

\section{EL IDEARIO FORMATIVO Y LAS HUELLAS DE UNA EDUCACIÓN QUE TRANSITÓ DESDE EL DISCIPLINAMIENTO A LA PSEUDO-MILITARIZACIÓN}

La escuela lo que busca es disciplinar no sólo el alma, sino también el cuerpo, encauzarlo por senderos de normalidad a partir de reglamentos y dispositivos diversos: unos más directos y soberanos, otros más indirectos y sutiles (FOUCAULT, 2002). En un plano individual, el resultado son sujetos dóciles y disciplinados. A escala global, a fines del siglo XIX y comienzos del XX en el sur de Chile, el telos constituyente de la escuela fue consolidar un proyecto de Estado-nación de Chile con una idea de educación monocultural. Desde este posicionamiento, la cuestión educativa en Chile históricamente ha sido pensada aislando el cuerpo de toda reflexión e investigación, reduciendo su abordaje al campo de la motricidad humana. Por consiguiente, esta perspectiva pedagógica es profundamente dualista ya que ha puesto su interés hegemónico en la relación cuerpo-mente, cuya premisa indica que es la mente la facultad más importante en educación. Los discursos, imágenes y prácticas que moldearon el cuerpo desde finales del siglo XIX hasta llegar a mediados del siglo XX en Chile se insertaron en la escuela con la finalidad de producir cierto tipo de sujeto: el ciudadano chileno occidentalizado (MAYORGA, 2017; MANSILLA y QUILAQUEO, 2018). 
Fig. 2. Padre Leonardo con un grupo de niños en la Escuela Misional de Quilacahuin, aprox. 1910. Indianercolleg von Quilacahuin. P. Leonard u. Lehrerin Margarita Pichicona Puchi. Trad. Colegio de indios de Quilacahuin. P. Leonardo y profesora Margarita Pichicona Puchi

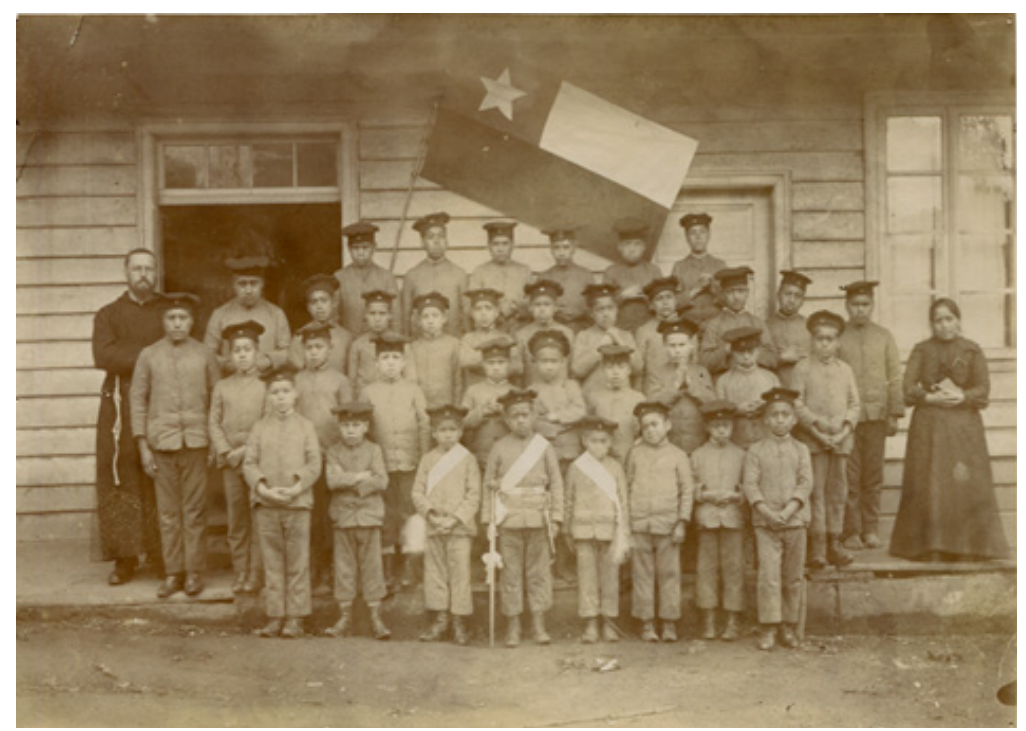

Los bávaros establecieron escuelas misionales de primeras letras en sus misiones, e internados en puntos geográficos y políticos estratégicos en el territorio, respondiendo a su proyecto disciplinador, y a las características de padrón de asentamiento mapuche. Sin embargo, tal como lo plantea MOLIENAUX (2016), a través de la educación en escuelas e internados, los capuchinos implementaron una 'táctica de confianza', como la hemos llamado, basado en el interés por el estudio del idioma de los mapuche y la tolerancia (no necesariamente aceptación) por las prácticas culturales indígenas. A través del lenguaje los religiosos lograron un conocimiento genuino sobre la sociedad mapuche, elaborando una fecunda producción de obras de distinta naturaleza que indagan en el conocimiento de los hábitos y las costumbres mapuche. A diferencia de las acciones del Estado de Chile y de los misioneros protestantes, cuyo énfasis integracionista radicaba en la negación cultural y el desprestigio asociado a la estigmatización lingüística, los capuchinos bávaros mostraron un interés por la lengua y la cultura mapuche, opción que generó debate al interior de la propia misión (NOGGLER, 1972). 


\section{Fig. 3. Recepción con banderas chilenas a los misioneros capuchinos,}

aprox. 1920

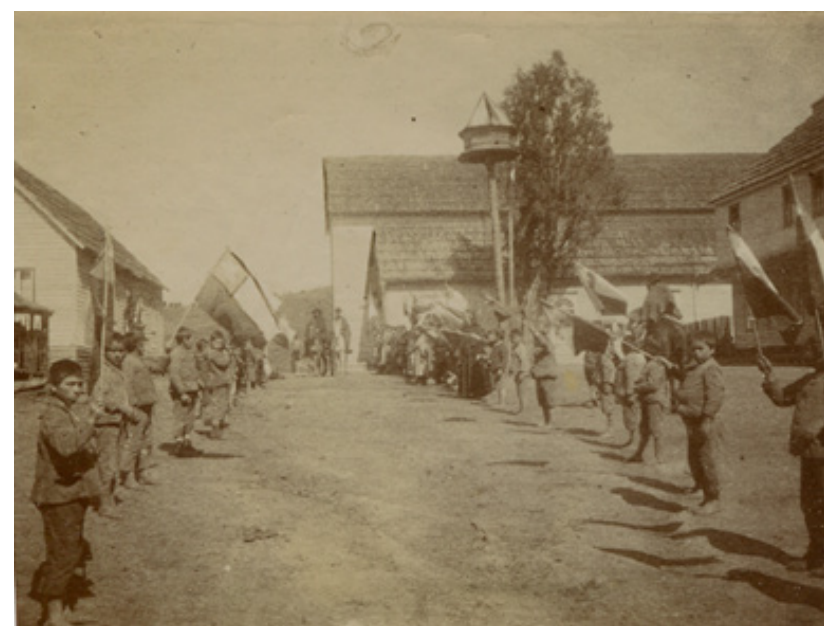

Los internados tenían el objetivo de educar, evangelizar, y sobre todo, vincular a los indígenas a la vida nacional chilena. Eran presentados como instituciones de civilización y garantía de un trabajo eficiente entre los mapuche; en estos centros, los misioneros intentaban cambiar el comportamiento de los niños indígenas, y por medio de la enseñanza de valores católicos, pretendían un nuevo individuo evangelizado y civilizado. En los colegios misionales con internado, los capuchinos tuvieron como norma general, que nunca se dejase a los niños sin vigilancia y que los misioneros "los trataran con mucho cariño" para que guardaran un buen recuerdo de la misión (NOGGLER, 1972, p. 145). Los internados pueden considerarse instituciones 'totales', es decir, un espacio que reúne a un gran número de individuos en igual situación, aislados de la sociedad por un periodo apreciable de tiempo, que comparten en su encierro una rutina diaria, administrada formalmente (GOFFMAN, 1956). En este sentido, las escuelas y los internados se constituyeron en eficientes dispositivos para crear y recrear de modo sistemático la comunidad imaginada (ANDERSON, 1993). Ese fue el modelo, y su implementación en la Araucanía fue diversa. 


\section{Fig. 4. Colegio de Panguipulli, aprox. 1915, aprox.}

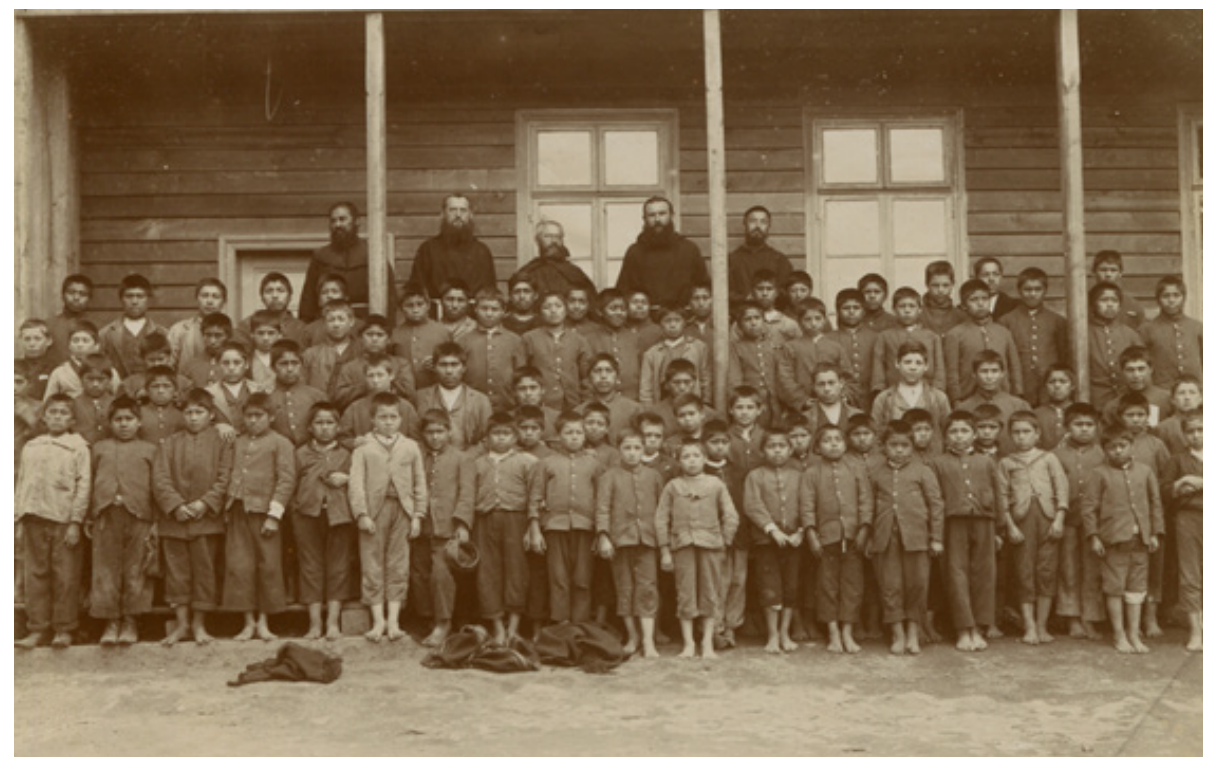

En definitiva, la instalación de la escuela chilena en territorio indígena afectó los propios procesos formativos dentro de la sociedad mapuche, los kimches (personas con conocimiento ancestral) son reemplazados por profesores y escuelas, las rogativas mapuche (gijatun o kamarrikun) comienzan a desarrollarse con menos frecuencia y los estudiantes al permanecer internos en algunos periodos no participarán de estas importantes ceremonias. El saber de la nueva cultura germana, chilena y occidental comienza a desplazar los saberes mapuches (QUILAQUEO, 2010; MANSILLA, 2018).

\section{CONSIDERACIONES FINALES}

Un sistema educativo con elementos militares, tales como: castigos, filas por tamaño, formaciones, timbres anónimos, respeto irrestricto a las reglas, notas estandarizadas, contenidos iguales, uniformes, agrupación por edades, horarios estrictos, la organización vertical y la obligatoriedad, desfiles tipos marchas en actos patrióticos conmemorativos, junto a extensas jornadas dedicadas al ensayo de esos desfiles, recrean un sistema semejante a las prisiones y ejércitos, lo que la hace incapaz de entregar una educación eficiente que considere las realidades y particularidades individuales de cada estudiante y su entorno. 
Lo que interesó copiar en Chile, se basó en un mecanismo de control, donde la aplicación no fue la idea en sí, sino la forma de aplicación de ésta en el contexto del proceso de construcción nacional alemán. Con la educación alemana que llegó a Chile, reaparece el concepto que había pensado y difundido Fichte en el Plan de Educación Nacional, cuyo propósito eje era el desarrollo desde edades tempranas del sentido de pertenencia a una nación. Por consiguiente, en Chile y en Alemania a fines del siglo XIX, el sistema educativo tenía que formar más desde el punto de vista del comportamiento (bilden) que desde el conocimiento (ausbilden).

Esta importante tendencia cultural que caracteriza este periodo está marcada por la fuerte influencia del liberalismo europeo y el romanticismo, generando en los grupos dirigentes y la clase ilustrada de Chile una actitud que sobrevaloraba lo foráneo, lo que se expresó no solamente en la vida cotidiana (comida, vestuario, expresiones lingüísticas, fiestas, modas), sino, en el modelo educativo implementado.

Se visualiza una notoria influencia de la epistemología pedagógica de Herbart en el discurso curricular de los preceptores alemanes en Chile. Los prototipos y lecciones-modelo, destacan la reflexión en la acción, la importancia de la sabiduría práctica, de la experiencia y la observación persistente del mundo de la vida (lebenswelt). El término que resume esta cuestión es "pedagogía científica", cuya retórica fue el eje del discurso pedagógico en la primera mitad del siglo XX en los principales congresos educacionales que se llevaron a cabo. Es el inicio de la profesionalización del profesorado en Chile. Desde lo anterior, la discusión sobre la pertinencia del modelo pedagógico alemán implementado en Chile queda abierta, más aun en consideración de la realidad social que enmarca el actual desarrollo político ideológico que domina la región latinoamericana.

\title{
REFERENCIAS
}

\begin{abstract}
ANDERSON, B. (2006). Comunidades imaginadas. Reflexiones sobre el origen y la difusión del nacionalismo. México: Fondo de Cultura Económica.
\end{abstract}

\author{
ARCHIVO CAPUCHINO DE LA UNIVERSIDAD CATÓLICA DE \\ EICHSTÄTT-INGOLSTADT. 1906. AltöttingerFranziskusKalender 1906. \\ Eichstätt (Alemania).
}


AZÓCAR, A.; NITRIHUAL, L.; FLORES, J.; LÓPEZ, S.; PACHECO, S (2015). La tarjeta postal fotográfica y la escuela misional en La Araucanía: El discurso visual capuchino sobre sus logros en la transformación de la niñez mapuche (1898- 1930). Revista Signa (24), 215-230.

CATRIQUIR, D. (2014). Desempeño del profesor de Educación Intercultural Bilingüe: criterios evaluativos desde la voz del lof che. Polis, Revista Latinoamericana, 13(39), 301-330.

CORIAND, R. y Winkler, M. (1998).Der Herbartianismus die vergerssene Wissenschaftsgeschichte. Berlin: Weinheim.

DE LA BARRA, L. (2000). La pareja conceptual civilización-barbarie. Norte y Sur América. La novela indigenista de Lautaro Yankas. Ciberhumanitis, Chile, 14. Extraído de <http://web.uchile.cl/ publicaciones/cyber/14/ tx6ldelabarra. html>.

FLORES, J.; Azócar, A. (2002). Tarjetas postales de los capuchinos. Revista Aisthesis, Santiago, (35), 81-88, 2002.

FOUCAULT, M. (2002). Vigilar y castigar. Nacimiento de la prisión. Buenos Aires: Siglo XXI editores.

GOFFMAN, E. (1956). La presentación de la persona en la vida cotidiana. Buenos Aires: Amorrortu.

HOT, A. (2010). L'ecole des Premières Nations au Québec, Reseau de rechercheet de connaissances relatives aux peuplesautochtones. Reseau de rechercheet de connaissances relatives aux peuplesautochtones. Montreal (Canadá)

KREBS, R., Gazmuri, C. (1990). La Revolución francesa y Chile. Santiago: Universitaria.

LETELIER, V. (1885). Las escuelas de Berlín. Santiago: Imprenta Nacional.

LETELIER, V. (1885). La instrucción secundaria y la instrucción universitaria en Berlín. Santiago: Imprenta Nacional. 
MANSILLA, J., Llancavil, D., Mieres, M. \& Montanares, E. (2016). Instalación de la escuela monocultural en la Araucanía, 1883-1910: dispositivos de poder y Sociedad Mapuche. Revista Educação y Pesquisa, 42(1), 213-228. doi: 10.1590/S1517-9702201603140562

MANSILLA, J., Huaiquián, C. (2018). Enseñanza a la alemana: transferencia del modelo de escuela de Berlín a Chile a fines del siglo XIX. Revista Espacios 39(17), p. 26.

MANSILLA, J. (2018). Influencia alemana en la reforma de las Escuelas Normales de Preceptores y Preceptoras en el centro sur de Chile, 1883-1920. Revista de Historia de la Educación latinoamericana 20(31), 189-209.doi: $0.19053 / 01227238.8574$

MAYORGA, R. (2017). Una red educativa, cuatro escuelas, millones de ciudadanos: educación, Estado republicano y sociedad civil en Chile (1813-2011). En Historia política de Chile. 1810-2010. Tomo II, Estado y sociedad. Santiago de Chile: Fondo de Cultura Económica.

MOLINEAUX, B. (2016). Vigencia del Diccionario Araucano de Félix de Augusta, a cien años de su publicación. Boletín de Filología 51(1), 187-209.

NOGGLER A. (1972). Cuatrocientos años de misión entre los araucanos. Padre las Casas: Imprenta San Francisco.

QUILAQUEO, D. (2010). Saberes educativos mapuches: un análisis desde la perspectiva de los kimches", Polis, revista latinoamericana (26)

RÖTTINGEN, M. (1921). FuenfundzwanzigjaehrigeMissionsthaetigkeit der BayrischenKapuzinermissionaere in Araucanischen Mission Chiles, 1896-1921.Tomos I y II. Archivo Capuchino de la Universidad Católica de Eichstätt- Ingolstadt. Eichstätt (Alemania).

SARANGAPANI, P. (2017). Savoir, curricula et méthodespédagogiques: le cas de l'Inde. RevueInternationaled'Éducation de Sèvres. Sèvres. ColloqueL'éducation en Asie en 2014: Quelsenjeuxmondiaux? 74(2), 120-143. Hauts-de-Seine (Francia).

TODOROV, T. (2008). La conquista de América. La cuestión del otro. México: Siglo XXI editores. 
TUBINO, F. (2014). El trasfondo epistémico de los conflictos

interculturales". Contextualizaciones latinoamericanas 6(11), 1-15

JUAN MANSILLA SEPÚLVEDA, Investigador y académico de la Facultad de Educación-Universidad Católica de Temuco. Profesor en Historia y Geografía. Doctor en Filosofía y Letras.

E-mail: jmansilla@uct.cl

CATALINA RIVERA GUTIÉRREZ, Doctora en Educación-Universidad Católica de Temuco. Profesora de Educación Física D y R. Becaria Conicyt.

E-mail: cata.riverag@gmail.com

Recebido de outubro de 2019

Aprovado em outubro de 2019 